\title{
PERTUMBUHAN JAMUR Beauveria bassiana (Bals) Vuill DAN PATOGENISITASNYA TERHADAP HAMA KUTU DAUN KEDELAI (Aphis glycines Matsumura)
}

\author{
Rosma Hasibuan, Herlina Levilia, Lestari Wibowo \& Purnomo \\ Jurusan Agroteknologi, Fakultas Pertanian Universitas Lampung \\ J1. Soematri Brodjonegoro, No.1, Bandar Lampung 35145 \\ Korespondensi : E-mail: rosma@unila.ac.id
}

\begin{abstract}
ABSTRAK
Kutu daun Aphis glycines (Hemiptera: Aphididae) merupakan salah satu hama penting yang menyerang daun dan polong kedelai. Jamur Beauveria bassiana merupakan agensia hayati berpotensi untuk dikembangkan sebagai musuh alami hama kutu daun Aphis glycines. Penelitian ini bertujuan untuk mengetahui pertumbuhan dan pengaruh beberapa konsentrasi konidia jamur B. bassiana terhadap mortalitas hama kutu daun kedelai (A. glycines). Percobaan dilakukan di laboratorium yang terdiri atas: pengujian diameter koloni, viabilitas, kerapatan konidia dan patogenisitas. Jenis perlakuan adalah isolate Tegineneng, Sumberjaya dan Tanggamus. Sedangkan pengujian patogenisitas isolat terbaik menggunakan empat perlakuan konsentrasi yaitu kontrol (air steril), 2,90 × $10^{7}$ konidia ml- $^{-1}, 2,90 \times 10^{6}$ konidia ml $^{-1}$, dan 2,90 x $10^{5}$ konidia ml $^{-1}$ B. bassiana. Hasil percobaan menunjukkan bahwa isolat jamur $B$. bassiana nyata mempengaruhi pertumbuhan spora (diameter koloni) dan kerapatan spora, namun tidak berpengaruh nyata terhadap viabilitas spora. Pertumbuhan spora terbesar terjadi pada isolat Sumberjaya, namun kerapatan spora terbesar terjadi pada isolat Tegineneng. Viabilitas spora yang diuji berkisar antara 58,12\% - 67,40\%. Hasil percobaan menunjukkan bahwa jamur B. bassiana isolat Tegineneng merupakan isolat potensial dibandingkan isolat Sumberjaya dan Tanggamus. Mortalitas A. glycines tertinggi $(97,95 \%)$ terdapat pada perlakuan $2,90 \times 10^{7}$ konidia ml $^{-1}$ B. bassiana isolat Tegineneng.
\end{abstract}

Kata kunci : Beauveria bassiana, Patogenisitas, viabilitas, Aphis glycines.

\section{PENDAHULUAN}

Serangan hama merupakan salah satu faktor yang menyebabkan rendahnya produksi kedelai. Sudarmo (1998) menyatakan bahwa Aphis glycines (Hemiptera: Aphididae) adalah salah satu hama yang menyerang daun dan polong. Lebih lanjut AAK (2002) menjelaskan bahwa A. glycines mengisap daun dan batang yang dapat menurunkan produksi kedelai secara langsung maupun tidak langsung. Kutu ini menyerang tanaman kedelai sejak awal pertumbuhan hingga panen.

Salah satu agensia hayati yang potensial sebagai sarana pengendali hama adalah jamur Beauveria bassiana (Tengkano et al., 2007). Jamur B. bassiana dapat mengendalikan berbagai jenis hama antara lain: hama walang sangit ( Leptocorisa oratorius), wereng batang coklat (Nilaparvata lugens) pada tanaman padi, hama kutu (Aphis sp.) pada tanaman sayuran dan ulat grayak (Spodoptera litura) pada tanaman hortikultura (Malau et al., 2010).

Kefektifan pengendalian oleh jamur entomopatogen sangat dipengaruhi oleh konsentrasi jamur yang diaplikasikan, yaitu kerapatan konidia dalam setiap milliliter air. Dalam upaya meningkatkan keefektivan pengendalian, maka informasi tentang potensi isolat $B$. bassiana dan konsentrasi kandungan $B$. bassiana dalam menekan perkembangan kutu daun A. glycines sangat diperlukan.

\section{METODE PENELITIAN}

Penelitian ini dilakukan pada bulan Agustus 2012 - Maret 2013 di Laboratorium Hama Tumbuhan dan Laboratorium Penyakit Tumbuhan, Bidang Proteksi Tanaman, Fakultas Pertanian, Universitas lampung. Penelitian ini terdiri atas tiga percobaan yaitu: uji pertumbuhan jamur $B$. bassiana, uji patogenisitas beberapa isolat jamur $B$. bassiana dan uji konsentrasi isolat $B$. bassiana yang potensial. Rancangan percobaan yang digunakan dalam percobaan adalah Rancangan Acak Lengkap (RAL). Untuk uji pertumbuhan dan uji patogenisitas beberapa isolat, perlakuan terdiri atas tiga isolat $B$. bassiana dengan tiga ulangan, sedangkan untuk uji konsentrasi isolat yang potensial terdiri atas empat konsentrasi $B$. bassiana potensial $\left(10^{5} \mathrm{ml}^{-1}, 10^{6} \mathrm{ml}^{-1}, 10^{7} \mathrm{ml}^{-1}\right.$, dan kontrol $)$ dengan tiga ulangan. 
Serangga dikembangkan dan dipelihara pada tanaman kedelai yang ditanam di areal halaman laboratorium Hama Tumbuhan Universitas Lampung. Agar ketersediaan serangga uji ini tetap terjaga, penanaman kedelai dilakukan secara bertahap pada petak pertanaman. Selain itu, kedelai juga ditanam pada polibag yang diletakkan di sekitar petak pertanaman kedelai.

Media SDA merupakan media yang mengandung pepton. Sebanyak 1 liter media SDA dikomposisikan dari $40 \mathrm{~g}$ dextrose, $15 \mathrm{~g}$ agar, $5 \mathrm{~g}$ kasein, $10 \mathrm{~g}$ pepton, dan 1 liter air destilata. Semua bahan tersebut dimasukkan ke dalam tabung erlenmeyer kemudian ditutup menggunakan alumunium foil, dikencangkan dengan karet gelang dan dibungkus dengan plastik tahan panas. Selanjutnya semua bahan tersebut diautoklaf selama \pm 2 jam. Setelah itu, media tersebut diangkat dan didiamkan sebentar supaya sedikit lebih dingin namun tetap hangat. Kemudian media yang hangat tersebut dituangkan ke masing-masing cawan petri dalam ruangan Laminar Air Flow agar steril.

Isolat $B$. bassiana yang diuji dalam penelitian ini berasal dari 3 tempat, yaitu Tegineneng, Sumberjaya, dan Tanggamus. Kemudian semua isolat diperlakukan dengan proses yang sama yaitu isolasi untuk mempertahankan isolat murni. Isolasi dilakukan di Laboratorium menggunakan media SDA (Saborroud dextrose agar) kemudian melalui tahapan inkubasi selama 1- 1,5 bulan.

Pertumbuhan Jamur Beauveria bassiana. Uji pertumbuhan $B$. bassiana dilakukan dengan tiga tahapan, yang pertama pengukuran diameter jamur, yang kedua pengujian viabilitas $B$. bassiana, dan yang terakhir perhitungan kerapatan konidia $B$. Bassiana. Pengukuran diameter dilaksanakan pada koloni jamur dari masing-masing isolat sesuai dengan perlakuan. Pengukuran diameter koloni jamur dilakukan sebanyak dua kali yaitu dari garis diameter terpanjang dan garis diameter terpendek dan dari kedua pengukuran tersebut dihitung diameter rata-ratanya. Pengukuran dilakukan pada hari ke-3, ke-6, ke-9, ke-12, ke-15, dan ke-18 setelah isolasi.

Untuk menguji viabilitas konidia $B$. bassiana, menyiapkan media SDA di dalam preparat cekung yang kemudian ditetesi suspensi $B$. bassiana pada pengenceran konidia $10^{-1}$ dengan menggunakan mikropipet. Kemudian media dalam preparat cekung tersebut diinkubasi dalam ruangan isolasi selama 20 jam. Rata-rata konidia yang tumbuh dan tidak tumbuh dihitung di bawah mikroskop binokuler dengan perbesaran $10 \mathrm{x}$
40. Persentase rata-rata perkecambahan dihitung dengan rumus :

$$
\mathrm{V}=\frac{g}{g+u} \times 100 \%
$$

dengan $\mathrm{V}$ adalah persentase konidia yang berkecambah, g adalah jumlah rata-rata konidia yang berkecambah, dan u adalah jumlah rata-rata konidia yang tidak berkecambah.

Kerapatan konidia dihitung dengan menggunakan haemositometer dalam 5 kotak ukuran sedang dengan 3 kali ulangan. Semua pekerjaan penghitungan dilakukan di bawah mikroskop binokuler dengan perbesaran $10 \mathrm{x}$ 40. Kerapatan spora dihitung dengan rumus:

$$
\text { Kerapatan spora }=\frac{\text { Rata }- \text { rata jumlah spora }}{0,04 \times 0,1} \times 10^{3}
$$

dengan 0,04 adalah luas kotak sedang hemositometer, 0,1 adalah kedalaman hemositometer, dan $10^{3}$ adalah perhitungan per ml.

\section{Patogenisitas Beberapa Isolat Beauveria bassiana.} Masing-masing biakan jamur B. bassiana diambil sebanyak satu bor gabus (diameter $1 \mathrm{~cm}$ ), kemudian diencerkan dengan $10 \mathrm{ml}$ air steril dalam tabung reaksi lalu di kocok dengan menggunakan rotamixer hingga tercampur merata. Setelah itu, suspensi jamur disemprotkan pada serangga uji (A. glycines @ 40 ekor sebanyak $\pm 5 \mathrm{ml}$ dengan menggunakan modifikasi handsprayer (volume $20 \mathrm{ml}$ ). Pengamatan dilakukan setiap setiap hari selama 7 hari setelah aplikasi atau sampai serangga uji mati. Persentase mortalitas dihitung dengan menggunakan rumus:

$$
P I=\frac{\sum n}{\sum N} \times 100 \%
$$

dengan PI adalah persentase infeksi, $\mathrm{n}$ adalah serangga yang mati (ekor), dan $\mathrm{N}$ adalah jumlah serangga yang diuji (ekor).

\section{Patogenisitas Konsentrasi Isolat yang Potensial.} Percobaan ini dilakukan berdasarkan hasil dari percobaan patogenisitas beberapa isolat sebelumnya. Isolat yang digunakan dalam percobaan ini adalah yang menunjukan tingkat virulensinya tertinggi. Percobaan terdiri atas empat perlakuan konsentrasi (kandungan spora entomopatogen) kontol, $10^{5}, 10^{6}$ dan $10^{7}$ konidia $\mathrm{ml}^{-1}$. Pengamatan dilakukan setiap hari selama 7 hari setelah aplikasi atau sampai serangga uji mati. Persentase mortalitas dihitung dengan menggunakan rumus:

$$
P I=\frac{\sum n}{\sum N} \times 100 \% \text {. }
$$


dengan PI adalah persentase infeksi, $\mathrm{n}$ adalah serangga yang mati (ekor), dan $\mathrm{N}$ adalah jumlah serangga yang diuji (ekor).

Menurut Hasinu (2009), apabila terdapat kematian serangga uji pada kontrol $>20 \%$ maka persentase kematian terkoreksi dihitung berdasarkan rumus Abbot (1925):

$$
\mathrm{Pt}=\frac{(\mathrm{Po}-\mathrm{Pc})}{(100-\mathrm{Pc})} \times 100
$$

dengan Pt adalah \% kematian terkoreksi, Po adalah \% kematian pada perlakuan, dan Pc adalah \% kematian pada kontrol.

Data uji pertumbuhan jamur B. bassiana, uji patogenisitas beberapa isolat jamur $B$. bassiana dan uji konsentrasi isolat $B$. bassiana yang potensial dianalisis dengan sidik ragam (analysis of variance $=$ ANOVA) dan dilanjutkan dengan uji Beda Nyata Terkecil (BNT) pada taraf 5\% dengan menggunakan perangkat SAS.

\section{HASIL DAN PEMBAHASAN}

Hasil percobaan menunjukkan bahwa isolat $B$. bassiana yang diuji berpengaruh nyata terhadap pertumbuhan diameter koloni jamur. Diameter koloni jamur tertinggi terdapat pada isolat Sumberjaya sedangkan diameter yang terkecil terdapat pada diameter koloni jamur Isolat Tegineneng (Tabel 1).

Pada hari pertama setelah isolasi, jamur $B$. bassiana sudah mulai tumbuh. Selanjutnya hasil penelitian menunjukkan bahwa hari ke-3 setelah isolasi, diameter koloni jamur B. bassiana berbeda nyata antarisolat. Diameter terbesar adalah isolat yang berasal dari Sumberjaya $(3,28 \mathrm{~cm})$ dan diameter ini nyata lebih besar dari isolat Tanggamus $(2,95 \mathrm{~cm})$ dan Tegineneng $(1,05 \mathrm{~cm})$. Pada hari ke-6 dan ke-9 diameter koloni jamur terbesar juga berasal dari Sumberjaya, namun tidak berbeda nyata dengan isolat asal Tanggamus. Pada pengamatan selanjutnya (12 hsa, 15 hsa dan $18 \mathrm{hsa}$ ), diameter koloni jamur $B$. bassiana terbesar adalah isolat Sumberjaya nyata lebih besar dari isolat Tegineneng dan Tanggamus.

Berbeda dengan diameter koloni jamur $B$. bassiana, isolat $B$. bassiana yang diuji tidak berpengaruh nyata terhadap viabilitas jamur $B$. bassiana. Perkecambahan konidia jamur B. bassiana asal Tegineneng mencapai $67,40 \%$, namun tidak berbeda nyata dengan perkecambahan konidia asal Sumberjaya dan Tanggamus yang mencapai $60,99 \%$ dan $58,12 \%$.

Pengujian selanjutnya dalam uji pertumbuhan jamur $B$. bassiana adalah uji kerapatan spora jamur $B$. bassiana. Perhitungan kerapatan spora $B$. bassiana dilakukan sebelum aplikasi jamur. Hasil percobaan menunjukkan bahwa asal isolat $B$. bassiana yang diuji berpengaruh nyata terhadap kerapatan spora jamur $B$. bassiana. Kerapatan spora isolat $B$. bassiana asal Tegineneng $\left(13,28 \times 10^{6} \mathrm{ml}^{-1}\right)$ nyata lebih besar dibanding isolat Tanggamus $\left(9,90 \times 10^{6} \mathrm{ml}^{-1}\right)$, namun tidak berbeda nyata dengan isolat Sumberjaya $\left(12,95 \times 10^{6} \mathrm{ml}^{-1}\right)$ (Tabel 2). Menurut Herlinda et al. (2005), isolat yang berasal dari berbagai jenis inang dan berbagai daerah geografis yang berbeda dapat memberikan keragaman strain yang tinggi sehingga menyebabkan pertumbuhan dan produktivitas spora yang berbeda antarisolat jamur.

Hasil uji patogenisitas menunjukan bahwa semua isolat jamur Beauveria bassiana yang diuji mampu membunuh hama kutu daun Aphis glycines. Serangga A. glycine yang terinfeksi $B$. bassiana ditandai dari tumbuhnya miselium berwarna putih pada permukaan tubuh A. glycine. Miselium jamur mulai terlihat sejak hari ke 2 setelah kematian serangga uji. Pada pengamatan 1 hari setelah aplikasi (hsa), pengaruh perlakuan isolat jamur B. bassiana nyata dan pada saat

Tabel 1. Nilai tengah diameter koloni beberapa isolat jamur B. bassiana yang ditumbuhkan pada media SDA

\begin{tabular}{ccccccc}
\hline \multirow{2}{*}{ Perlakuan (Isolat) } & \multicolumn{7}{c}{ Diameter koloni $(\mathrm{cm})$} \\
\cline { 2 - 7 } & $3 \mathrm{his}$ & $6 \mathrm{hsi}$ & 9 his & $12 \mathrm{hsi}$ & $15 \mathrm{hsi}$ & $18 \mathrm{hsi}$ \\
\hline Tegineneng & $1,05 \mathrm{c}$ & $1,37 \mathrm{~b}$ & $2,03 \mathrm{~b}$ & $2,45 \mathrm{c}$ & $2,83 \mathrm{c}$ & $3,54 \mathrm{c}$ \\
Sumberjaya & $3,28 \mathrm{a}$ & $4,58 \mathrm{a}$ & $5,25 \mathrm{a}$ & $5,73 \mathrm{a}$ & $6,33 \mathrm{a}$ & $6,78 \mathrm{a}$ \\
Tanggamus & $2,95 \mathrm{~b}$ & $4,40 \mathrm{a}$ & $4,77 \mathrm{a}$ & $5,00 \mathrm{~b}$ & $5,28 \mathrm{~b}$ & $5,53 \mathrm{~b}$ \\
\hline Pr $>\mathrm{F}$ & $<, 0001^{*}$ & $<, 0001^{*}$ & $<, 0001^{*}$ & $<, 0001^{*}$ & $<, 0001^{*}$ & $<, 0001^{*}$ \\
\hline BNT & 0,2401 & 0,5641 & 0,5212 & 0,6821 & 0,7498 & 0,6633 \\
\hline
\end{tabular}

Keterangan : Nilai tengah yang diikuti dengan huruf yang sama menunjukkan tidak berbeda nyata berdasar uji BNT $\alpha=0,05$. 
ini, persentase kematian A. glycines masih sangat rendah. Namun pada pengamatan berikutnya ( 2 hsa, 3 hsa, dan 4 hsa) perlakuan isolat berpengaruh nyata terhadap kematian hama kutu A. glycines (Tabel 3).

Selanjutnya hasil pengujian menunjukkan bahwa isolat Tegineneng merupakan isolat potensial dibandingkan dengan isolat Sumberjaya dan Tanggamus. Pada pengamatan 2 hsa, 3 hsa, dan 4 hsa, mortalitas A.glycine oleh jamur B. bassiana isolat Tegineneng berbeda nyata dengan mortalitas A.glycine oleh jamur B. bassiana isolat Sumberjaya dan Tanggamus. Secara umum, mortalitas Aphis glycines terbesar terjadi pada isolat Tegineneng. Pada hari ke-4 setelah aplikasi, $B$. bassiana isolat Tegineneng dengan kerapatan konidia

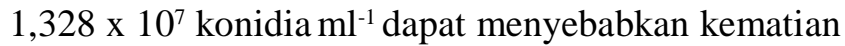
A.glycine mencapai $93,97 \%$ dan tidak berbeda nyata dengan isolat Sumberjaya yang kerapatan konidianya $1,295 \times 10^{7}$ konidia $\mathrm{ml}^{-1}$ dengan mortalitas mencapai $86,83 \%$, namun berbeda nyata dengan isolat Tanggamus yang berkerapatan spora $9,90 \times 10^{6} \mathrm{konidia} / \mathrm{ml}$ dengan mortalitas mencapai $82,91 \%$.

Dari hasil pengujian sebelumnya menunjukkan bahwa jamur B. bassiana asal Tegineneng merupakan jamur yang potensial, sehingga isolat Tegineneng digunakan untuk pengujian patogenisitas dengan beberapa konsentrasi jamur $B$. bassiana . Hal ini dapat dilihat dari hasil pengukuran kerapatan konidia jamur, viabilitas spora juga patogenisitas ketiga isolat jamur $B$. bassiana. Secara umum, isolat Tegineneng merupakan isolat yang pontensial dibandingkan isolat Sumberjaya dan Tanggamus.

Hasil uji patogenisitas menunjukan bahwa semua tingkat kerapatan spora $B$. bassiana yang diuji mampu membunuh hama kutu daun Aphis glycines (Tabel 4). Dari penelitian yang telah dilakukan diperoleh hasil yang menunjukkan bahwa konsentrasi konidia berpengaruh nyata dalam membunuh A. glycine. Pada pengamatan 2 hari setelah aplikasi, kematian kutu daun berkisar $7,74 \%-15,84 \%$ dan mortalitas ini tidak berbeda nyata antarkonsentrasi yang diuji. Namun pada pengamatan 3 hsa, larutan B. bassiana berkerapatan $2,90 \times 10^{7}$ konidia $\mathrm{ml}^{-1}$ dapat menyebabkan kematian serangga uji mencapai $65,11 \%$ dan mortalitas ini nyata lebih tinggi dibandingkan dengan larutan B.bassiana berkerapatan $2,90 \times 10^{6}$ konidia $\mathrm{ml}^{-1}$ dan $2,90 \times 10^{5}$ konidia $\mathrm{ml}^{-1}$ yang menyebabkan kematian serangga masih di bawah $50 \%$. Pada hari ke-4 setelah aplikasi, mortalitas A. glycine berbeda nyata antarisolat, mortalitas serangga yang

Tabel 2. Nilai tengah viabilitas dan kerapatan spora konidia beberapa isolat jamur B. bassiana

\begin{tabular}{ccc}
\hline Perlakuan (Isolat) & Viabilitas spora $(\%)$ & Kerapatan spora $\left(10^{6} \mathrm{konidia} \mathrm{ml}^{-1}\right)$ \\
\hline Tegineneng & 67,40 & $13,28 \mathrm{a}$ \\
Sumberjaya & 60,99 & $12,95 \mathrm{a}$ \\
Tanggamus & 58,12 & $9,90 \mathrm{~b}$ \\
\hline Pr $>$ F & $0,299^{\text {tn }}$ & $0,0029^{*}$ \\
\hline BNT & 13,49 & 1,51 \\
\hline
\end{tabular}

$\overline{\text { Keterangan : Nilai tengah yang diikuti dengan huruf yang sama menunjukkan tidak berbeda nyata berdasar uji }}$ BNT $\alpha=0,05$.

Tabel 3. Nilai tengah mortalitas hama kutu daun Aphis glycines terkoreksi oleh beberapa isolat jamur B. bassiana

\begin{tabular}{ccccc}
\hline \multirow{2}{*}{ Perlakuan (Isolat) } & \multicolumn{4}{c}{ Mortalitas Aphis glycines (\%) } \\
\cline { 2 - 5 } & 1 hsa & 2 hsa & 3 has & 4 hsa \\
\hline Tegineneng & 0,83 & $16,94 \mathrm{a}$ & $65,11 \mathrm{a}$ & $93,97 \mathrm{a}$ \\
Sumberjaya & 0,00 & $10,60 \mathrm{~b}$ & $54,71 \mathrm{~b}$ & $86,83 \mathrm{ab}$ \\
Tanggamus & 0,00 & $9,72 \mathrm{~b}$ & $52,81 \mathrm{~b}$ & $82,91 \mathrm{~b}$ \\
Kontrol & 0,00 & $0,00 \mathrm{c}$ & $0,00 \mathrm{c}$ & $0,00 \mathrm{c}$ \\
\hline Pr > F & $0,4411^{\text {tn }}$ & $0,0003^{*}$ & $<, 0001^{*}$ & $<, 0001^{*}$ \\
\hline BNT & 1,39 & 4,80 & 6,53 & 7,75 \\
\hline
\end{tabular}

Keterangan : Nilai tengah yang diikuti dengan huruf yang sama menunjukkan tidak berbeda nyata berdasar uji BNT $\alpha=0,05$. hsa: hari setelah aplikasi, his: hari setelah isolasi. 
Tabel 4. Nilai tengah mortalitas hama kutu daun Aphis glycines terkoreksi padabeberapa konsentrasi jamur $B$. bassiana isolat Tegineneng

\begin{tabular}{ccccc}
\hline \multirow{2}{*}{ Konsentrasi $\left({\text { konidia } \mathrm{l}^{-1} \text { ) }}\right.$} & \multicolumn{4}{c}{ Mortalitas Aphis glycines (\%) } \\
& $1 \mathrm{hsa}$ & $2 \mathrm{hsa}$ & $3 \mathrm{hsa}$ & $4 \mathrm{hsa}$ \\
\hline $2,90 \times 10^{7}$ & 0,00 & $15,84 \mathrm{a}$ & $65,11 \mathrm{a}$ & $97,95 \mathrm{a}$ \\
$2,90 \times 10^{6}$ & 0,00 & $13,12 \mathrm{a}$ & $43,38 \mathrm{~b}$ & $87,43 \mathrm{~b}$ \\
$2,90 \times 10^{5}$ & 0,00 & $7,74 \mathrm{ab}$ & $38,68 \mathrm{~b}$ & $80,23 \mathrm{c}$ \\
Kontrol & 0,00 & $0,00 \mathrm{~b}$ & $0,00 \mathrm{c}$ & $0,00 \mathrm{~d}$ \\
\hline Pr > F & - & $0,0489^{*}$ & $<, 0001^{*}$ & $<, 0001^{*}$ \\
\hline BNT & - & 11,235 & 7,362 & 6,3251 \\
\hline
\end{tabular}

Keterangan : Nilai tengah yang diikuti dengan huruf yang sama menunjukkan tidak berbeda nyata berdasar uji BNT $\alpha=0,05$.

disebabkan oleh larutan B. bassiana berkerapatan 2,90 x $10^{7}$ konidia/ml mencapai $97,95 \%$, sedangkan $B$. bassiana berkerapatan $2,90 \times 10^{6}$ dan $2,90 \times 10^{5}$ dapat menyebabkan kematian sebesar $87,43 \%$ dan $80,23 \%$.

Hasil penelitian ini sejalan dengan hasil penelitian yang telah dilakukan oleh Atdmaja et al. (2010), yang menyatakan bahwa semakin tinggi kerapatan konidia yang digunakan, maka semakin banyak spora yang dikandungnya sehingga semakin banyak spora yang menempel pada serangga inang, yang selanjutnya akan menyebabkan kematian pada serangga tersebut. Selanjutnya, Junianto dan Sulistyowati (2000) melaporkan bahwa kemampuan $B$. bassiana untuk menginfeksi serangga dipengaruhi oleh konsentrasi, viabilitas dan virulensi. Pada konsentrasi rendah perlu waktu yang lebih lama untuk mematikan serangga daripada konsentrasi tinggi.

Hasil penelitian Atdmaja et al. (2010) menunjukkan B. bassiana dengan konsentrasi spora $10^{8}$ konidia $\mathrm{ml}^{-1}$ dapat menginfeksi Helopeltis antonii sebesar 76,66\% dalam waktu 5 hari. Selain itu, hasil penelitian Indriyati (2009) menunjukkan bahwa aplikasi jamur B. bassiana di lapang pada Aphis sp. dengan kerapatan spora $10^{7}$ konidia $\mathrm{ml}^{-1}$ dapat mengakibatkan mortalitas rata-rata sebesar 78,8\% hingga hari ke-5 setelah aplikasi. Hal ini menunjukkan bahwa virulensi dari jamur $B$. bassiana yang digunakan dalam penelitian ini cukup tinggi.

\section{KESIMPULAN}

Hasil percobaan menyatakan bahwa pertumbuhan jamur B. bassiana (dinyatakan dalam diameter koloni dan kerapatan konidia) berbeda nyata antarisolat yang diuji. Diameter koloni terbesar terjadi pada isolat Sumberjaya, dan kerapatan konidia terbesar terjadi pada isolat Tegineneng. Namun, pertumbuhan jamur B. bassiana berupa viabilitas spora tidak berbeda nyata antarisolat yang diuji.

Selanjutnya isolat $B$. bassiana berpengaruh nyata terhadap mortalitas kutu daun (Aphis glycines) yang diuji. Semua isolat (Tegineneng, Sumberjaya, dan Tanggamus) dapat menyebakan kematian pada kutu. Jamur B. bassiana asal Tegineneng merupakan isolat yang lebih potensial dibandingkan dengan isolat Sumberjaya dan Tanggamus. Pada hari ke-4 setelah aplikasi patogenisitas isolat Tegineneng menyebabkan mortalitas A. glycines sebesar 93,97\%.

Patogenisitas isolat Tegineneng yang diuji dengan beberapa konsentrasi konidia spora berbeda nyata antarperlakuan. Semakin tinggi konsentrasi konidia jamur yang digunakan, maka semakin besar mortalitas yang terjadi pada kutu daun A. glycines.

\section{DAFTAR PUSTAKA}

AAK. 2002. Kedelai. Kanisius. Yogyakarta.

Atmaja, W.R., T.E. Wahyono dan A. Dhalim. 2010. Aplikasi beberapa strain Beauveria bassiana terhadap Helopeltis antoni Sign pada bibit jambu mete.Bul. Litro. 21(1):37-42.

Hasinu. 2009. Isolasi dan uji patogenitas Bacillus thuringensis terhadap Crocidolomia binotalis Zell. (Lepidoptera:Pyralidae). J. Budidaya Pertanian, 5(2): 84-88.

Herlinda, S., E. Mayang, S. Pujiastuti, Suwandi, E. Nurnawati dan A. Riyanta. 2005. Variasi virulensi strain-strain Beauveria bassiana (Bals.) Vuill. terhadap larva Plutella xylostella (L.) (Lepidoptera: Plutellidae). J. Agritrop. 24(2):5257. 
Indriyati. 2009. Virulensi jamur entomopatogen Beauveria Bassiana (Balsamo) terhadap kutu daun (Aphis Spp.) dan kepik hijau (Nezara viridula). J. HPT Tropika, 9(2): 92-98.

Junianto, D. dan Sulistyowati. 2000. Produksi dan aplikasi Beauveria bassiana untuk pengendalian penghisap buah kakao (Helopeltis spp.) dan penggerek buah kakao (Conomorpha cramerella). Simposium Kakao, 2000. Pusat Penelitian Kopi dan Kakao. Jember : 17 hal.
Malau, M., A. Sofyan, dan Yusriadi. 2010. Pengujuan jamur Beauveria bassiana (Bals.) Vuill isolat asal Banjar Baru dalam menekan perkembangan hama tanaman. J. Agroscientiae 17(2):101-105.

Sudarmo, S. 1998. Pengendalian Serangan Hama Kedelai. Kanisius. Yogyakarta $31 \mathrm{hlm}$.

Tengkano, W., Supriyatin, Suharsono, Bedjo, Y. Prayogo, dan Purwantoro.2007. Status hama kedelai dan musuh alami pada agroekosistem lahan kering masam Lampung. Iptek Tanaman Pangan, 3: 93-100. 